\title{
Tipos de esfoliação facial: efeito benéfico e reações adversas
}

\section{Types of facial exfoliation: beneficial effect and adverse reactions}

\author{
Enilda Graciella Mutte Soares ${ }^{1}$ \\ Marcello Mascarenhas ${ }^{2}$
}

\section{RESUMO}

Introdução: A esfoliação facial é um método que contribui na melhoria das células da pele do rosto, através da remoção das células mortas, estimulando a renovação celular. Este método é utilizado para retirar impurezas atribuídas pelos mais diversos fatores que influenciam na aparência e também na saúde da pele. Para a realização de uma esfoliação pode-se utilizar substâncias abrasivas, equipamentos e formulações químicas que possuem a mesma finalidade. Objetivo: Diferenciar tipos de esfoliação facial para cada biotipo de pele em relação efeito benéfico e reações adversas através de uma revisão bibliográfica. Metodologia: 0 estudo de revisão utilizou a base de dados Pubmed e Scielo, utilizou descritores em saúde na língua portuguesa, espanhol e inglesa publicados no período de 2002 até 2019, além de livros da área, utilizando como descritores esfoliação facial, biotipos cutâneos, tratamentos faciais , esfoliação e reações adversas. Conclusões:Dentre os mais diversos tipos de tratamentos estéticos a esfoliação facial juntamente com os peelings têm sido os mais procurados como um recurso terapêutico para a melhoria da pele. Os benefícios aparecem, com o ganho de luminosidade da pele e também na renovação celular. Pode haver a ocorrência de efeitos adversos com o aparecimento de hipocromias e hipercromias.Para uma melhor escolha dos procedimentos a serem feitos, é fundamental a seleção de um bom profissional para a realização do tratamento e um atendimento personalizado.

\section{PALAVRAS-CHAVE}

Pele; esfoliação; facial; renovação celular; efeito benéfico; reações adversas

\footnotetext{
${ }^{1}$ Discente do Curso de Biomedicina do Centro Universitário Metodista - IPA, Porto Alegre - RS.

${ }^{2}$ Docente do Curso de Biomedicina do Centro Universitário Metodista - IPA, Porto Alegre - RS.
} 


\begin{abstract}
Introduction: Facial exfoliation is a method that contributes to the improvement of facial skin cells by removing dead cells, stimulating cell renewal. This method is used to remove impurities attributed by various factors that influence the appearance and health of the skin. For the exfoliation one can use abrasive substances, equipment and chemical formulations that have the same purpose. Objective: To differentiate facial exfoliation types for each skin biotype in relation to beneficial effect and adverse reactions through a literature review. Methodology: The review study used the Pubmed and Scielo database, used health descriptors in Portuguese, Spanish and English published from 2002 to 2019, as well as books in the area, using as descriptors facial exfoliation, skin biotypes, treatments. facials, exfoliation and adverse reactions. Conclusions: Among the most diverse types of aesthetic treatments, facial exfoliation along with peelings have been the most sought after as a therapeutic resource for skin improvement. The benefits appear with the gain of skin brightness and also in cell renewal. Adverse effects may occur with the onset of hypochromias and hyperchromias.For a better choice of procedures to be done, it is essential to select a good professional to perform the treatment and personalized care.
\end{abstract}

\title{
KEYWORDS
}

Pele; esfoliação; facial; renovação celular; efeito benéfico; reações adversas. 


\section{INTRODUÇÃO}

Em uma sociedade que estima a beleza e possui referenciais estéticos preestabelecidos, a pele pode ser colocada como um "cartão de visitas", que provoca, assim, os pontos de vistas críticos e exigentes dos indivíduos (ALMEIDA, 2014). A pele é a forma de apresentação do indivíduo por ser o maior órgão do corpo, que tem a finalidade de barreira contra o meio ambiente e é dividida em três camadas ( DE BARBA; RIBEIRO, 2010). Sua composição apresenta duas camadas de tecido a epiderme e a derme, com a fundamental finalidade de envoltório exterior do organismo o qual representa 15 $\%$ do peso corporal. (BORGES, 2010).

A epiderme é a estrutura mais externa composta por células epiteliais que tem função de proteção com agentes infecciosos, absorção ou eliminação de substâncias e também síntese de vitamina D. A derme, estrato médio, é composta por tecido papilar e reticular e fibras de elastina e colágeno que dão sustentação à epiderme. E a hipoderme é a mais profunda, composta por adipócitos, ou seja, células de gordura que tem principal função de isolante térmico (BARBOSA,2010). A pele atua como um revestimento protetor do corpo. Preservando os órgãos internos contra choques, lesões, queimaduras e substâncias corrosivas, possui ainda outras funções como controlar a temperatura, sensorial, absorção da radiação solar. (FERNANDES, 2011).

A aparência da pele é aprimorada por tratamentos estéticos que têm evoluído nos dias atuais. Há diversas áreas do cuidado da pele que podem ser abordadas, entre elas a esfoliação, a qual consiste em um método de fundamental para eliminação de células mortas e/ ou danificadas, desta maneira promovendo renovação celular e reepitelização através do uso de ativos (RIBEIRO, 2010).

0 aspecto da pele gradativamente passa por modificações de acordo com a idade, sendo que na pele essas alterações são mais reconhecidas facilmente. Mudanças nas características da pele durante o envelhecimento são frequentemente definidas por fatores ambientais ou extrínsecas, tais como radiação ultravioleta, assim como por fatores intrínsecos alguns deles relacionados ao tecido conjuntivo (ORIA, 2003).

Nesta busca de melhorias para pele existem diversos tipos de procedimentos estéticos que podem ser feitos, dentre eles a esfoliação facial (ALMEIDA, 2014). A esfoliação facial é um procedimento que auxilia na renovação da cútis, promovendo remoção das células superficiais, as quais apresentam baixo teor de queratina e pouca vitalidade. A técnica consiste em eliminar impurezas, facilitando a entrada de ativos para revigorar o local e assim promovendo uma aparência mais saudável (PIMENTAL, 2008).

Os esfoliantes mostram mecanismos de ação diferenciados e podem ser classificados de acordo com seu agente gerador: físico, químico ou enzimático. 0 mecanismo ação dos esfoliantes atua reparando hiperpigmentação, queratose, rugas finas através do uso de diversos ativos que por sua eficácia promovem a ação benéfica. Todos os ativos dependem de diversos fatores como pH do meio, tempo de contato com a pele e concentração na formulação (ALMEIDA,2014).

Nesse contexto, o nosso artigo tem como objetivo diferenciar tipos de esfoliação facial para a pele bem como relacionar os efeitos benéficos e reações adversas através de uma revisão bibliográfica.

\section{METODOLOGIA}

O estudo foi uma revisão bibliográfica, que utilizou a base de dados Pubmed e Scielo, baseando-se nos seguintes descritores em saúde na língua portuguesa, espanhol e inglesa: esfoliação facial, biótipos cutâneos, tratamentos faciais e esfoliação, serão utilizadas de forma isolada ou combinada. Além da busca dos descritores em livros da área.

Foram incluídos artigos e livros entre 2002 e 2019, e também foram usadas algumas referências clássicas. Também foram excluídos artigos e livros que não tenham como foco principal a face e estudos anteriores a 2002, desde que não sejam considerados artigos de referência.

Após a revisão na base de dados foram selecionados os títulos, posteriormente procedeu-se a leitura dos resumos, quando foram se enquadrando no tema de estudo, foi procedida a leitura do artigo na forma integra e foram organizadas de forma sistematizada definindo temas que foram abordados: pele e suas funções, esfoliações, peelings e reações adversas, por fim foi feita uma análise crítica, de forma conclusiva, apresentada ao final do artigo, de acordo com o grau de relevância. 


\section{RESULTADOS}

\section{Pele e suas funções}

A pele pode variar de pessoa para pessoa, assim foi didaticamente dividida em: Normal ou eudérmica: pele ideal, secreções equilibradas. Pele lipídica ou oleosa: espessura aumentada, $\mathrm{pH}$ ácido, aspecto oleoso e com brilho intenso. Pele seca ou alípica: secreção sebácea insuficiente, pessoas de pele muito clara, fina e sensível, frágil e naturalmente irritável. Pele mista: pele oleosa na zona T, restante aspecto ressecado (RIBEIRO, 2010). (Quadro I)

Quadro 1-Tipos de pele e suas características.

\begin{tabular}{|l|l|}
\hline Tipo de Pele & Característica de cada tipo \\
\hline Normal ou eudérmica & $\begin{array}{l}\text { Superfície lisa, aveludada, } \\
\text { brilho normal }\end{array}$ \\
\hline Oleosa ou lipídica & $\begin{array}{l}\text { Espessura ampliada, maior } \\
\text { brilho }\end{array}$ \\
\hline Seca ou alípica & $\begin{array}{l}\text { Sem brilho, desidratada, } \\
\text { opaca }\end{array}$ \\
\hline Mista & Oleosa e laterais seca \\
\hline
\end{tabular}

Fonte: Elaborado pela autora.

A classificação da pele ocorre devido a avaliação de vários fatores, entre eles a lubrificação, que é o óleo que a pele produz, a hidratação, que é a capacidade que ela tem de absorver água em seu meio, e a coloração, tanto do ponto de vista genético, melânico, como do ponto de vista "sanguíneo" (KEDE,2015). A avaliação da pele é feita através de uma anamnese considerada um procedimento clássico, com ênfase aos hábitos de exibição solar ao longo da vida e no histórico endocrinológico que pode requerer exames que complementam o histórico familiar (BRAND ,2009).

Uma pele normal é considerada ideal, apresenta espessura mediana, secreção sebácea equilibrada, cor tendendo para o róseo, tônus e elasticidade uniformes, superfície lisa e aveludada, brilho normal e poros não perceptíveis. A pele oleosa possui espessura ampliada, engrossada e com acentuação dos sulcos de expressão, se caracterizando pela produção excessiva de óleo, que lhe confere maior brilho e estimula abertura dos poros, principalmente na zona $\mathrm{T}$ ou central (testa, nariz e queixo) (RIBEIRO; 2010; STEINER,2012).
A pele oleosa ou lipídica é gordurosa e brilhante, apropriado ao acrescimento das secreções sebácea e sudorípara, geneticamente definidas. Sua densidade está elevada e a textura é granulosa. Os orifícios pilossebáceos estão aumentados e há tendência ao tamponamento folicular (KEDE, 2015).

Via de regra, ela é bem resistente, tolerando melhor as agressões e envelhecendo vagarosamente, em alguns casos, é desidratada (pouca água), são mais suscetíveis à seborreia. Pele seca apresenta pouca produção sebácea, é opaca, sem brilho e desidratada. A falta água da pele seca se agrava pela carência de óleo, que tem a propriedade de impedir a sua evaporação. Sua espessura é bem fina, os poros diminuídos, o aspecto descamativo. Sendo pouco elástica, mostram-se finas rugas e com tendência ao envelhecimento precoce. Pele mista é uma condição de pele muito comum, sua zona T ou central tem aspectos de pele oleosa e as partes laterais, de pele seca. A pele sensível constitui de pele fina, seca, avermelhada e sensível, reagindo mais rápido aos cosmecêuticos, apresenta vasos dilatados em geral na superfície, chamados de telangiectasia (STEINER, 2012).

\section{Esfoliação}

Em busca de uma pele saudável, sem marcas e manchas é importante esfoliá-la. A esfoliação é responsável pela renovação das células através da remoção das mortas e o estimulo da produção das novas, com mais colágeno (DEPREZ, 2009).

A esfoliação se refere a um procedimento utilizado a fim de recuperar uma pele mais saudável criando células novas e favorecendo a ação do colágeno, que irá promover uma pele com a aparência melhor. É uma técnica que pode se utilizar para fins estéticos ou também de forma medicinal, sendo a estética agradável .E um fator importante para o bem-estar psicossocial (GERSON, 2011).

A esfoliação facial é um método que colabora na melhoria das células da pele, pois consiste em retirar células da superfície que estão abarrotadas de queratina com escasso conteúdo hídrico e sem vitalidade. A retirada desta camada, além de eliminar impurezas e absorção de ativos, reconduz á pele sua fisionomia natural melhorando sua textura e uniformidade obtendo como resultado melhor apresentação (ALMEIDA, 2015).

0 hábito de esfoliar limpa profundamente, evitando os temidos cravos e espinhas. Além disso, elimina as im- 
purezas, que se acumulam nos poros e impedem a ação correta dos dermocosméticos, obtendo-se um resultado mais eficaz destes produtos (FERNANDES, 2011). Os esfoliantes podem ser divididos de acordo com o seu modo de ação e agentes utilizados. Os esfoliantes físicos agem por método mecânico de arraste de células superficiais por intermédio de substâncias abrasivas. Entre as mais usadas, podemos citar a sílica, semente de apricot, arroz, microesferas de jojoba, semente de damasco refinada, cirebelles, microgrânulos de polietileno. A eficácia e o incômodo da esfoliação podem ser variados e isso depende do tamanho do grânulo usado e também da pressão aplicada para fazer a abrasão (BAGATIN, 2009).

A técnica de esfoliação é realizada com produto abrasivo que remove as células mortas estimulando renovação celular e, diminuindo a espessura da epiderme, facilitando a absorção de princípios ativos. A esfoliação superficial pode atingir apenas a epiderme, ocasionando um eritema. A esfoliação intermediária atinge a epiderme e parte da derme, ocasionando uma hiperemia e edema. A esfoliação profunda atinge todas as camadas da derme, ocasionando um sangramento associado a outros sinais inflamatórios controlados. Podem ser utilizados aparelhos específicos para a esfoliação mais agressiva a pele (OLIVEIRA, 2008).

A esfoliação física ou mecânica usa substâncias abrasivas para o refinamento da camada córnea. Age pelo atrito da ação mecânica estimulada pela pressão provocada pela pele e as mãos. 0 produto pode ser feito em creme, gel e gel creme. Os esfoliantes que atuam nesse mecanismo podem ser naturais de origem vegetal, mineral, marinha, derivados orgânicos sintéticos formadores de filme e carboidratos.Há ainda a esfoliação física e mecânica realizada por meio de equipamentos eletroterápicos (DEPREZ, 2009).

0 peeling de diamante é feito através de um aparelho com uma manopla e diferentes ponteiras diamantadas de granulometrias distintas. Logo, o peeling é um equipamento próprio para propiciar uma microesfoliação da camada mais superficial da pele, a epiderme, com objetivo de remover as células mortas que resta na epiderme e estimular a produção de colágeno (BORGES, 2010).

Peeling de cristal é realizado por meio de uma ponteira que aplicada sobreposta a pele libera e aspira os cristais (oxido de alumínio) pelo próprio equipamento a vácuo. Ele é indicado para peles fotoenvelhecidas e que necessitam de uma esfoliação mais profunda. 0 peeling de cristal é o mais dolorido, trazendo uma suave queimação, ocasionando vermelhidões na pele (ANDREWS ,2011). A reestruturação é um processo tão importante quanto a esfoliação mais estruturado, porém essencial a qual corpo seria incapaz de sobreviver, abrange atuações integradas das células, matriz celular e mensageiros químicos que visam renovar a integridade do tecido atingido e com lesão o mais rápido possível (DE AMORIM, 2015).

Os esfoliantes podem agir por mecanismos químicos ,físico ou enzimático sua aplicação promove uma melhoria na hiperpigmentação , queratose actínea e rugas finas (ALMEIDA,2007)

A esfoliação enzimática ou biológica, como o peeling que usa enzimas proteolíticas capazes de promover renovação celular por meio de hidrólise de ligações específicas entre os aminoácidos que formam a queratina da camada córnea diminuindo a espessura da camada a pele inicia um processo de regeneração celular com estimulação da formação de fibras de colágeno e elastina (OLIVEIRA,2008)

Na classificação dos esfoliantes químicos, as formulações dos ativos mais usados em produtos cosméticos são: ácido glicólico, ácido lático e ácido glicólico tem sido o mais utilizado (SOUZA, 2004). 0 procedimento de esfoliação química com a utilização de um ácido orgânico pode ser resultante da redução da coesão entre as células do estrato córneo, proporcionando a descamação e, por fim, um estrato córneo mais flexível e compacto (ALMEIDA, 2014).

\section{Peeling químico}

0 peeling pode ser classificado como muito superficial, agindo no estrato córneo até o estrato granuloso; superficial, ativando na epiderme, do estrato granuloso até a camada basal, sendo que ambos podendo ser utilizados por esteticistas, peelings médios, agindo na derme papilar e profundo até a derme reticular, restritos a área médica. 0 peeling químico é categorizado de acordo com a profundidade da pele a ser obtida, onde o muito superficial é aquele que atinge somente na camada córnea, o superficial na epiderme, o médio na derme papilar e o profundo alcança a derme reticular (DE AMORIM, 2015). Os peelings muito superficiais afinam e retiram o estrato córneo e não criam lesão abaixo do estrato granuloso (FERNANDES ,2011). 
Os Peelings químicos estabelecem uma esfoliação acelerada ou injúria à pele induzida por agentes cáusticos que causam danos controlado, seguido pela liberação de citocinas e mediadores da inflamação, resultando em espessamento da epiderme, depósito de colágeno, reorganização dos elementos estruturais e aumento do volume dérmico. A profundidade depende do tipo de pele, tratamentos prévios, local anatômico, desengorduramento, técnica de aplicação e agente (VELASCO, 2004).

0 peeling pode ser realizado com produtos cosméticos que possuam substâncias que alterem a estrutura córnea como ácidos, enzimas ou substânicas abrasivas .Quando se utiliza os ácidos (Quadro II) é importante diferenciar o tipo e sua ação (FERNANDES ,2011; BRAND, 2009) .

Quadro 2 - Peeling: tipo de ácido e ação sobre a pele.

\begin{tabular}{|c|c|}
\hline Tipo de ácido & Ação na pele \\
\hline Glicólico & $\begin{array}{l}\text { Despigmentante, hidratante e } \\
\text { queratolítico }\end{array}$ \\
\hline Retinóico & Queratolítico e esfoliante \\
\hline Mandélico & Renovador Celular \\
\hline Salicílico & Queratolítico, antifúngico e \\
\hline Láctico & anti-inflamatório \\
\hline Benzóico & Clareador, antifúngico, e \\
\hline Málico & renovador celular \\
\hline & Fungistático e antisséptico \\
\hline & Renovador celular \\
\hline Resorcina & $\begin{array}{l}\text { Antioleosidade, antiacneico e } \\
\text { renovador celular }\end{array}$ \\
\hline Hialurônico & $\begin{array}{l}\text { Hidratante, regenerador e } \\
\text { restaurador dos tecidos }\end{array}$ \\
\hline Kójico & $\begin{array}{l}\text { Despigmentante e anti- } \\
\text { irritativo }\end{array}$ \\
\hline Glicirrízico & Anti-inflamatório e antialérgico \\
\hline Azelaico & Antiacneico e despigmentante \\
\hline Fítico & Despigmentante \\
\hline Hidroquinona & Despigmentante \\
\hline Benzóico & Fungistático e antisséptico \\
\hline Tricloracético & Cáustico e vesicante \\
\hline Alfalipóico & Antioxidante \\
\hline
\end{tabular}

Fonte: Elaborado pela autora.
0 peeling feito com ácido glicólico é raramente irritante e pouco foto sensibilizante, sendo caracterizado por não ter impacto tóxico a nível sistêmico. Contudo, deve-se sempre analisar a concentração do ácido a ser utilizado, visando sempre o nível superficial (ZAMPRONIO, 2012). O princípio ativo esfoliante químico mais usado como co-adjuvante nos Produtos Cosméticos Despigmentantes é o ácido glicólico.

$\mathrm{O}$ ácido glicólico (AAH) é o mais comumente usados em peeling químicos em consultórios de dermatologia e por esteticistas. É popularmente conhecido como "peeling da hora do almoço", porque pode ser realizado durante a hora do almoço do paciente e ele pode voltar a seu trabalho sem nenhum sinal indicador (ALAM; GLADSTONE, 2010). 0 ácido glicólico (alpha-hydroxy acid ou AHA) é mais utilizado em procedimentos que visam o rejuvenescimento facial, pois promove uma leve esfoliação conforme a concentração. Em concentrações mais baixas entre (5 a 15\%) ocorre a diminuição de coesão dos corneócitos nas regiões superficiais do extrato córneo. Em altas concentrações (50 a 70\%), possui efeitos menos específicos, porém mais profundos, pois há uma diminuição da força de coesão dos queratinócitos, ocorrem modificações na derme papilar, reticular e dérmica. É importante lembrar que o pH e a concentração do ácido glicólico são relevantes para definir sua segurança e eficácia. Quanto menor o pH maior é a irritação na pele, quanto maior o pH menor será sua irritação. Muitos produtos com ácido glicólico geralmente tem o pH adequado entre 3,0 e 5,0 para serem compatíveis com o pH da pele $(4,2$ a 5,6), e podem ser estimulantes para a pele sensível. Após a aplicação do ácido, deve-se ter cuidados como evitar ao máximo a luz solar e utilizar um protetor ou bloqueador solar (YAAR, 2007).

0 ácido glicólico é um tipo de alpha-hidroxiácido retirado da cana de açúcar que possibilita uma melhora na textura, no tônus e uniformidade da tonalidade da pele, pois minimiza a espessura da camada córnea hiperqueratínica, proporcionando diminuição da coesão ou adesividade entre os corneócitos e suas camadas (TEDESCO, 2007). Os alfa-hidróxiacidos se diferenciam pela dimensão da molécula, sendo o ácido glicólico de menor cadeia carbônica e, logo, com maior poder de penetração na pele (DE AMORIM, 2015). Além do ácido glicólico, existem outros princípios ativos esfoliantes que permitem a renovação celular superficial da pele 
que são: ácido láctico, ácido tartárico, AHA’s (Alpha-Hidroxi-Ácidos), azeloglicina, extrato de tangerina japonesa e extrato de vitis vinífera (TEDESCO, 2007).

0 ácido retinóico é conhecido por induzir uma série de processos celulares, como crescimento e diferenciação celular. Vários mecanismos de ação associados ao ácido retinóico são descritos, como separação dos grânulos do pigmento nos queratinócitos, mediação na transferência dos melanossomos e aceleração do turnover celular, o que minimiza o excedente de pigmento (ALMEIDA, 2014)

Os ácidos reagem com a enzima "cimentante" que se encontra entre a queratina, proporcionando a esfoliação da superfície acelerando assim a renovação celular. A mudança de $\mathrm{pH}$ leva a ruptura das ligações de queratina, a abertura dos folículos pilo sebáceos, ajudando na permeabilidade da pele. e tornando a permeação transepidérmica mais eficaz. Desta forma resulta, através da renovação celular, na melhora da textura da pele, e revitalização, tornando a superfície cutânea mais lisa, clara, luminosa e assim diminuindo rugas superficiais. Além disso, há o estímulo aos fibroblastos, aumento do colágeno, proporcionando à pele mais resistência e flexibilidade, redução de cloasmas solares superficiais e aumenta a síntese do metabolismo basal (RIBEIRO, 2010).

O Ácido Mandélico é um derivado da hidrólise de um extrato de amêndoas amargas. È considerado um dos alfa-hidroxiácido (AHA'S) de maior peso molecular, contribuindo com um efeito uniforme. Manifesta uma dupla função de atividade antibacteriana e queratolítico. É indicado para hiperpigmentação, tratamento da acne, rejuvenescimento e foliculites.A concentração usual e de 30 a $50 \%$ podendo ser utilizada nas peles de fototipos $\mathrm{l}$ ao $\mathrm{V}$ com intervalos de 10 a 15 dias (ALMEIDA, 2014).

O ácido salicílico Beta hidroxiácido é um composto lipofílico que retira lipídeos intercelulares e apresenta características anti-inflamatória e antimicrobiana. São bem toleradas por todos os fototipos cutâneo. Em concentrações $0,5 \%$ até $3 \%$ tem atividade queratoplástica e em concentrações de $4 \%$ a $20 \%$ comporta-se como queratolítico. É apropriado para acne, rosácea, hiperpigmentação e dano solar. Podem ser usados em sabonetes, shampoo, loções e gel. A aplicação do ácido salicílico em áreas e concentrações maiores pode gerar quadro tóxico conhecido como salicilismo (VELASCO, 2004).
0 ácido lactobiônico é comumente encontrado no leite, tendo amplo utilização comercial, devido a sua forte atividade antioxidante através da quelação do ferro e da inibição da oxidação de outras substancias rapidamente oxidéveis, como a antralinae hidroquinona (SOUZA, 2008).

A profundidade de penetração do peeling químico é como resultado de alguns fatores como $\mathrm{pH}$ (potencial hidrogênio) e concentração do produto a ser utilizado (KEDE ,2015).0 procedimento de microdermoabrasão consiste na aplicação direta sobre a pele de um equipamento mecânico gerador de pressão negativa e positiva simultânea e quimicamente inertes (DEPREZ, 2009). As principais indicações de tratamentos com peeling químico são diversas como: sardas, hiperpigmentação pós-inflamatória, discromias, fotoenvelhecimento, oleiras, acne vulgar, rosácea, estrias, cicatrizes entre outras (BRAND, 2009). Esse tipo de método tem diversos objetivos, dentre eles: rugas, melanoses, queratóses actínicas, estrias, melasma, hiperpigmentação pós-inflamatória, acnes e suas sequelas, cicatrizes atróficas, queratose pilar e para clareamento da pele. Entretanto é não é recomendado nos casos de fotoproteção inadequada, gravidez, estresse ou escoriações neuróticas, uso de isotretinoína oral há menos de seis meses, cicatrização deficiente ou formação de queloides, história de hiperpigmentação pós-inflamatória permanente, dificuldade para compreender e seguir orientações fornecidas (PIMENTEL, 2008).

0 peeling químico é utilizado como recurso terapêutico para o envelhecimento cutâneo, pois compreende na esfoliação da pele aplicando um agente ou vários agentes que vão ocasionar a renovação da epiderme e gerar um tecido vigoroso com melhor aparência que o primeiro. 0 peeling é classificado em superficial, médio e profundo devido ao seu pH e concentração (MIKOSKI; OLIVEIRA, 2017). Adequado para atuar nas manchas senis, melasmas, acnes, vários tipos de cicatrizes, estrias e redução das linhas de expressão. A esfoliação é controlada de acordo com a destruição e regeneração do tecido. É significativo para o rejuvenescimento, pois ocasiona maior hidratação, maleabilidade e ampliação da formação de células de colágeno e elastina que vão constituir um aspecto uniforme e jovem a pele. A utilização do peeling químico não é apropriado para peles que apresentam algum tipo de lesões e os indivíduos 
que se encontram em fase de tratamento devem fazer o uso de protetor solar regularmente (ZDEBSKI, 2014).

\section{Reações Adversas}

Sendo procedimentos dermatológicos ou estéticos como qualquer outro, o tratamento por meio de peelings químicos também está suscetível à ocorrência de algumas complicações. Em geral, essas complicações estão associadas a fatores específicos como a indicação incorreta do procedimento, orientações escassas ou não obedecidas pelo paciente e/ou má técnica de aplicação, dentre as quais estão: carreamento do agente para áreas não tratadas com risco de cicatrizes, conjuntivite, úlcera de córnea, diluição do agente pela lágrima, escoriações levando a infecções e hiperpigmentação, hipopigmentação, erupção acneiforme, linhas de demarcação, dermatite de contato irritativa ou alérgica, eritema ou prurido persistente, cicatrizes atróficas ou hipertróficas e efeitos tóxicos (PEREIRA \& MEJIA, 2016).

É muito importante investigar se o paciente tem histórico de má cicatrização de lesões, formação de quelóides, hiperpigmentação pós-inflamatória, pacientes que não querem ou não podem deixar de se expor ao sol, fatores que devem ser considerados e dados relevância. Pode acontecer erro do profissional, no controle da camada da pele desejada (GOMES, 2009). Complicações mais comuns originadas por um peeling químico são esfoliações prematuras, infecções, erupções acneiformes, equimoses, hiperpigmentação pós-inflamatória, hipopigmentação, reações alérgicas, eritema persistente e fibrose. Na maioria das ocorrências, estas complicações podem ser reversíveis (ALMEIDA DE SÁ, 2007). As reações adversas ocasionais envolvem o surgimento de bolhas, crosta, queimadura grave ou rubor, edema na pele, escurecimento, ou clareamento da pele, sensação de calor ou urticante, descamação da pele, a qual pode ocorrer depois de poucos dias de tratamento (GOMES, 2009).

\section{CONSIDERAÇÕES FINAIS}

Esfoliação facial é um processo pelo qual utiliza-se técnicas para o aprimoramento e refinamento da pele, no entanto isso depende dos tipos de pele e das diversas formas de como tratar essa pele de acordo com cada perfil. Os tratamentos e os cuidados são fundamentais para manter uma pele mais vigorosa e saudável. Para a

determinação do tratamento adequado existem dois fatores fundamentais para a realização: a anamnese e a união dos processos a serem realizados de acordo com o tipo de pele a ser aplicado.

Esfoliação é o ato de remover as camadas de células mortas da pele, através de meios físicos que pode ser feito com produtos que contenham grânulos ou, químicos que são realizados com agentes ácidos ou ferramentas especificas. Essa técnica tem como principal objetivo limpar a pele profundamente através do uso de cremes, sabonetes ou óleos específicos que proporcionam essa ação esfoliante. Pode ser utilizado os ácidos como forma de tratamento o peeling ou grânulos mais finos ou mais grossos em produtos esfoliantes.Com o auxílio desses produtos as impurezas são retiradas através da descamação ou abrasão da mistura em contato com a pele.

Os benefícios da esfoliação a pele são os mais diferenciados. Entre eles pode-se incluir a remoção das células mortas, o aumento da luminosidade da/ pele, a diminuição de manchas, no controle da oleosidade e ainda pode potencializar os tratamentos de pele. Por se tratar de um método abrasivo a pele necessita de um cuidado maior após o processo do peeling, isso pode depender de qual técnica foi realizada para obter melhor resultado, é indicado fazer o uso de hidratantes para que essa pele consiga se regenerar. Logo em seguida ao peeling são raros os efeitos adversos, porém pode apresentar sintomas como um aspecto de queimadura de segundo grau e poderá ocorrer uma vermelhidão, após alguns dias do tratamento feito, também poderá apresentar algumas áreas da pele mais escura por haver uma reação, um vírus ou até mesmo uma bactéria

Portanto, quando o tratamento feito através do peeling é extremamente satisfatório, pode obter resultados benéficos a saúde da pele do rosto. Essa conduta reduz a oleosidade da pele, reduz e até elimina rugas e sinais do envelhecimento, devendo se observar a frequência de realização em torno de 15 a 30 dias. Os cuidados primordiais à pele compreendem não exposição ao sol, evitando o toque na área tratada para que não haja irritação e também é indicado a utilização de cremes hidratantes para manter a pele saudável. Assim, a esfoliação através do peeling deve ser realizada com profissionais experientes e antes mesmo de realizar o procedimento deve haver um diálogo com o responsável a fim de minimizar as reações adversas possíveis de ocorrer. 


\section{REFERÊNCIAS}

ALAM, Murad; GLADSTONE, Hayes B.; TUNG, Rebecca C. Dermatologia cosmética. Elsevier Brasil, 2010.

ALMEIDA Ciancaglio Garbossa, Wanessa, Garcia Mercurio, Daiane, Berardo Gonçalves Maia Campos, Patricia Maria, Ácido chiquímico para esfoliação cutânea. Surgical \& Cosmetic Dermatology 2014.

ALMEIDA DE SÁ, E. J. Peeling de TCA. Rio de Janeiro - RJ, 2007. Disponívelem:http://www.cbmce.com.br/monografias/dr edson_jose_almeida_de_Sa.pdf Acesso em 22 de outubro de 2019.

ALMEIDA, Emily Frizzo de .Utilização do ácido glicólico nas alterações estéticas Revista, Personalité , São Paulo,v11,n.53,p. 124-134,set/out.2007

ANDREWS, Samantha; LEE, Jeong Woo; PRAUSNITZ, Mark. Recovery of skin barrier after stratum corneum removal by microdermabrasion. AAPS PharmSciTech, v. 12, n. 4, p. 1393 $1400,2011$.

BAGATIN, Ediléia; HASSUN, Karime; TALARICO, Sérgio. Revisão sistemática sobre peelings químicos. Surgical \& Cosmetic Dermatology, v. 1, n. 1, p. 37-46, 2009.

BARBOSA, Alcione Oliveira; MEJIA, Dayana Priscila Maia. Peelings Químicos no Rejuvenescimento Facial. 2010.

BORGES, F. S. Dermato-funcional: modalidades terapêuticas nas disfunções estéticas. In; GARCIA, P.G (Org.). Fotodocumentação em fisioterapia Dermato-funcional. São Paulo: Phorte, 2010, p561-81.

BRAND, Vínicius C. et al. Avaliação da intensidade das rugas periorbitais por processamento digital de imagens: um estudo de validação. Surgical \& Cosmetic Dermatology, v. 1, n. 1, p. 15-20, 2009.

DE AMORIM, Monthana Imai; PIAZZA, Fátima Cecília Poleto. uso das argilas na estética facial e corporal. 2015.

DE BARBA, Juliane; RIBEIRO, Elisiê Rossi. Efeito da microdermoabrasão no envelhecimento facial. A REVISTA, p. 6, 2009. EPREZ, P. Peeling químico: superficial, médio e profundo. Rio de Janeiro: Revinter, 2009.

DO AMARAL, Cíntia Netto et al. Tratamentos em Estrias: um levantamento teórico da microdermoabrasão e do peeling químico. 2015.

FERNANDES, Aliciara Carlos Flor et al. PEELING QUIMICO COMO TRATAMENTO ESTÉTICO.2011.

GERSON, Joel et al. Fundamentos de estética 3-Ciência da pele. São Paulo: Cengage Learning, 2011.
KAREN GEREMIA, Karen, Fontanive, Tiago, Mascarenhas, Marcello. 0 efeito do desoxicolato de sódio no tratamento da gordura localizada: estudo de revisão. Ciência em Movimento Reabilitação e Saúde, n. 38, v. 19, on line, 2017.

KEDE M. P; SABATIVITCH.O. Dermatologia Estética", Rio de Janeiro. $3^{\circ}$ Edição Editora Atheneu 2015

MIKOSKI, Rosana Geis; DE OLIVEIRA, Silvia Patrícia. Tratamento e prevenção de manchas senis nas mãos, utilizando o peeling de ácido salicílico e protetor solar.2017.

OLIVEIRA, A. L.; PEREZ, E. Estética Facial: Curso Didático de estética. Vol. 2. São Caetano do Sul, SP: Yendis, 2008.

ORIÁ, Reinaldo B. etal. Estudo das alterações relacionadas com a idade na pele humana, utilizando métodos de histo-morfometria e autofluorescência Study of age-related changes in human skin using histomorphometric and autofluorescence approaches. An Bras Dermatol, v. 78, n. 4, p. 425-434, 2003.

PEREIRA, A. M. V.; MEJIA, D. P. M. Peelings químicos no rejuvenescimento fácil. Faculdade Cambury Bio Cursos, 2016.

PIMENTEL , Arthur dos Santos. Peeling, máscara e acne :seus tipos e passo a passo do tratamentoestético.São Paulo:LMP,2008

RIBEIRO, CLAUDIO. Cosmetologia Aplicada a Dermoestética 2a edição. Pharmabooks,

SOUZA, V. M de Ativos dermatológicos :guia de ativos dermatológicos utilizados na farmácia de manipulação para médicos e farmacêuticos. 2.ed. São Paulo:Tecnopress,2004.

STEINER, Denise. Beleza levada a serio.4. Ed: Ridee. São Paulo, 2012.

TEDESCO, Ionice R.; ADRIANO, Jerusa; SILVA, Danielle. Produtos cosméticos despigmentantes nacionais disponíveis no mercado. Santa Catarina, 2007

VELASCO, Maria Valéria Robles et al. Rejuvenescimento da pele por peeling químico: enfoque no peeling de fenol Facial skin rejuvenation by chemical peeling: focus on phenol peeling. An Bras Dermatol, v. 79, n. 1, p. 91-99, 2004.

YAAR, Mina. Manifestações Clínicas e Histológicas dos Envelhecimentos Cutâneos Intrínsecos e Extrínsecos. In GILCHREST, Bárbara A, KRUTMANN, Jean Envelhecimento Cutâneo. Editora Guanabara Koogan, Rio de Janeiro, 2007.

ZAMPRONIO, Franciele Pereira Castro. Atuação da fisioterapia dermato-funcional das disfunções estéticas decorrentes da gravidez. 2012.

ZDEBSKI, Ana Claudia et al. UTILIZAÇÃo DO ÁCIDO GLICÓLICO A 10\% PARA REVITALIZAÇÃO DE PELES MADURAS. Revista Thêma et Scientia, v. 4, n. 1, p. 127-130, 2014. 